\title{
XIX.
}

\section{Kurze Bemerkungen über die Ostseebäder von Westpommern und Rügen, nebst einigen vergleichend-histologischen Beobachtungen.}

\author{
Von Rud, Vircbow.
}

I.

Pommern bat auf seiner bei 60 Meilen langen Küste wenige und sehr mässige Häfen, aber fast überall einen Sirand, der zum Baden vortrefflich geeignet ist. Der Besuch der pommerschen Küste nimmt daher von Jahr zu Jahr melar $z$, jngbesondere seitdem durch Eisenbahnen und Dampfschiffe bequeme Verbindungen eröfinet sind. Die ejgentlichen Strandbewohner benutzten früher die ihnen so nahe Gelegenheit sehr wenig, und noch jetzt trifft man Gegendến genug, wo die Fischer, die doch einen grossen Theil ihrer Tage und Nächte auf dem Neere zubringen, des Badens wegen sich gar nicht ins Wasser begeben. Ja, die grösste Mebrzall! dieser Leute versteht nicht einmal zu scliwimmen; weil sie der Meinung sind, es sei besser, sofort unterzugehen, als nach einem langen, mühevollen Kampfe aum Ende doch zu unterliegen. Ist es doch rorgekommen, dass eine Mutter es für das grösste Unglück hielt, dass ihr Soln zu den Pioniren eingezogen wurde, weil er dạ schwimmen lernen würde!

Es war daher fast nur die gebildete Bevöllkerung, weìche das Seebad suchte, und die Badeorte fanden sich hauptsächlich bei den Städten sowohl, wie bei Kolberg, Rïgenwalde, Stolpmünde, als in den benachbarten Dörfern, wie in Sorenbohm und Nest bei Köslin, Henkenhagen bei Kolberg u. s. w. Nur Swinemünde und Putbus zogen eine grössere Zahl von Fremden herbei, weil thre hequeme lage, die günstigeren Einrichtungen, die Gelegenheit zu weiteren Ausflügen sie besonders bevorzugten. Als indess mit der Entwickelung des Verkelirs das Bediurfniss sich mehrte, und namentlich die Dampfschifflinien von Stettin aus immer mehr fremde Besucher in der Richtung auf Swinemünde und Rügen heranbrachten, suchte 
man neu€, günstige Punkte auf, und der glänzende Erfolg von Heringsdorf ermunterte sowohl den Eifer der Privaten, als die Sorge der Behörden. Am meisten zeigt sich gegenwärtig dieser Einfluss auf den Delta-Inseln der Oder, Usedom und Wollin, auf weicher letzteren namentlich Misdroy schon ein schwerer Nebenbuhler firr Heringsdorf geworden ist. Allein auch auf Rägen lat sich die Aufmerksamkeit allnälig von Putbus auf besser gelegene Pankte des Strandes gewendet, und ror Allen hat Sassnitz auf der Halbinsel Jasmund in wenigen Jabren eine schnelle Entwickelung genommen.

Ein vierwöchentlicher \&ufenthalt, den ich während des letzten Herbstes in diesen Gegenden nahm, hat mir Gelegenheit gegeben, manche Beobachtungen dayubber zu wiederholes, die ich schon in frïheren Zeiten gesammelt hatte, und einige neue Punkte zu sehen. Fine lurze Mitheilung derselben erscheint um desshalb gerechtfertigt, weil durch die rorwiegende Neigung zt den Nordsee- und atlantischen Büdern selbst die Aufmerksamkeit der Aerzte etwas abgelenkt ist. Manches Vorurtheil läuft dabei mit, indem man bald die bekannte geistige Hichtung einzelner Männer als den Typus der ganzen einheimischen Bildung betrachtet, bald die Anschauungen von einigen Chaussee - oder Eisenbahntouren auf das gesammte Land ïberträgt. Beides ist gleich unrichtig.

Pommern ist wesentlich Seeland. Po mure heisst am Meere. Im Osten beginnt es mit einem Hölıenzuge, der in der Nähe der Küste bis über 1000 Fusš Par. ansteigt und sich dann, von zahlreichen, grossen and fischreichen Seen unterbrochen, an der Südgrenze fortsetzt, indem er sich sowoll gegen die Küste, als gegen das oderbecken allmälig abdacht. Der ganze östliche und südliche Theil von Hinterpommern ist daber bergig und lügelig, wäbrend die Küste im Ganzen flach erscheint, da die wirklichen Ausläufer des Grenzhöhenzuges, wie der Gollenberg bed Köslin, gewöbnlich in einiger Entfernung von der See verstreichen (vgl. C. Wolff, Charalkteristik der Oberfächengestalt von Hinterpommern vom Gollenberg östlich, in den Baltischen Studien. 1839. Heft I. C. Sprengel, Einige Nachrichten und Bemerkungen äber die natürlichen, landwirthschaftlichen und gewerblichen Verhältnisse Hinterpommens in der Allg. Landwirthsch. Monatsschrift. Köslin, 1840. I. 1. 9. 25).

Das Festland von Vorpommern ist zum grossen Theil eben, berïhrt aber das eigentliche Meer so wenig, dass es hier ausser Betracht. bleiben kann. Rïgen dagegen ist, wie bekannt, eine sebr unebene Inşel; deren Berge bis zu 500 Fuss ansteigen, und dabei zum Theil ganz senkrecht zur See abfallen. Auch die Inseln des Oder-Deltas besitzen Höhen, die freilich von geringerer Bedentung sind, indess bei der Nähe des Ufers doeh beträchtlich genug erscheinen. Ihr Clarakter ist jedoch durchaus verschieden, indem die Abstiurze der rügianischen Küste der Kreide, dagegen die grösseren Höhen der ganzen ïbrigen Küste entweder der Thon- und Graukohlenformation (vgl. v. 0ey nha u sen, Bemerkungen auf einer mineralogischen Reise durch Vor- und Neupommern, in Karstens Archiv f. Bergbau und Hüttenwesen. 182\%. HIL. 2), oder ier Dënenbildung angehören. Vur auf Wollin finäen sibh noch einzelne Reste der hrejdeformation und zerstreut in Hinterpommern Heinere Hassen von jurassischen Grebilden anstehend. 
Es ergiebt sich daraus von selbst, dass die pommersche Küiste nirgends felsig ist, indem auch da, wo altere Formationen his unmittelbar an die See berantreten, der eigentliche Strand aus zerspülten und ausgewaschenen. Trümmern bestebt, welche meist einen festen, durchaus glatten, mehr oder weniger sandigen Boden bilden. Nur die östhiche rïgianische Küste und einige kleinere Abschnite der festländischen hahen einen steinigen Strand, der sehr wenige Möglichkeiten für bequeines Baden gewährt. In Rügen sind es namentlich Feuersteiné von allen Grössen und Farben und won den wunderlichsten Gestalten, welche als lackeres Geröl das tanze Seeufer bilden. Ueberall lagern sie in continuirlichen, sich von 4 zu 4 Fuss iibereinander wiederholenden Reihen in der Kreide, mit der sie sich loslösen, herabstürzen und nach der Auflösung der Kreide liegen bleiben. Zum Theil neben innen, aber an der festländischen Küste auch ganz isolirt, finden sich die mannichfaltigsten Geschiebe, namentlich die auch sonst über Pommern weit und breit ausgesäeten erratischen Blöcke, hie nnd da von den colossalsten Verhältnissen, und ausserdem zahlreiches Geröll aus den grossen Mergel- und Thonlagern. Am dichtesten finden sich diese gewöbnlich an denjenigen Stellen des Strandes, wo beträchtlichere Berge nnmittelbar herantreten, oder wo stelle Lelmwande von der Fluth bespült werden. An solchen Punkten erleidet das Land Jahr für Jahr die beträchtlichsten Yerluste and vergeblich hat man bis jetzt auf Mittel gesonnen, denselben vorzubeugen. Jede vom Ufer zurücksströmende Welle führt einige Theile des Ufers mit sich fort, urn sie entweder in einiger Entfernung wieder fallen zu las sen, oder auch sie bis auf grosse Strecken zu verschleppen. Aus dem ersteren Umstande erklärt es sich, dass fast die ganze pommersche Küste von melıreren parallelen Sandriffen begleitet ist, welche die Landung grösserer Schiffe nur an venigen Punkten zulassen; aus dem zweiten, dass die meisten Flussmïndungen versanden und allmälich für die Seliffahrt unbrauchbar werden. Swinemünde hat nur durch die kostbarsten Molenbauten vor der Versandung bewahrt werden könner, welche den nocl bis zam 14 ten Jahrhundert blïhenden Hafen von Regamünde vollständig vernichtet hat. Freilich tragen dazu die wandernden Dünen das jhrige bei (vgl. The besius, Beylräge, zu der Naturhistorie des Pommertandes in den Baltischen studien 1835. III. 1. Quandt, Ueber die Veluste der pommerschen Küste an die Ostsee. Ebendas. 1837. IV. 2).

Am günstigsten zum Baden ist daher der Strand an allen den Gegenden, wo derselbe von Dünen begrenzt ist. Denn die Dünen, welche übrigens an einzelnèn Orten eine Höhe von 100 bis 1 j0 Fuss elreichen, sind ja eben nur aus dem Flugsand hervorgegangen, welcher den Strand bedeckt und zur Zeit, wo die Sece niedrig ist, trocknet and dann vom Winde landeinwärts getrieben wird. Vor den Dünen breitet sich fast immer ein sandiger, in der Nähe des Wassers ganz fester, gewöhnlich 20 bis 30 Schritt breiter Strand aus; auf dem es wahrhaft angenehm ist, mit dem nackten Fuss zu gehen. Anf ihm stehen auch gewöbnlich die Radehütten, welche freilich nicht inmer vor der Ueberfluthung ganz gesichert, sind. Aber sein Aussehen ist ein äusserst wechselndes; jeder Tiag ändert seine Breite, seine Oberfläche, seine Bedeckung. Für den Naturforscher ist es namentich höchst lebrreich und unterhaltend, jun zur Zeit des niedrigsten Wasserstandes at beob- 
achten. Das Spiel der za- und abgehenden Wellen erzeugt dans die mannichfaltigsten Figuren an der Oberfläcle, in denen es doch nicht schwer wirc, eirs wiederkehrendes Gesetz zu entdecken, und die inshesondere sebr geeignet sind, die eigenthünlichen Oberfächenformen der einzelnen schichten des Wellenkalks, sowie die sonderbaren, verzweigten und verästelten Figuren zu erklären, welcbe auf den Spaitmächen des gewölanlichen Muschelkalks zun Vorschein kommen.

Die Dünenbildung ist an der pommerschen Küste die weitaus überwiegende. Nur in Rügen fehlt sie fast ganz und daher ist der Strand und die Meeresfläche hier nur an wenigen Stellen günstiger, z. B. Jei dem kleinen Badedorf Bink, wo dafư das Heer bis auf wenige Puntate ünsserst seicht. ist, Putbus lat gar nichts von Dünen, da es, wie die ganze Südküste von Rügen und die entsprechenie küste von Newrorpommern eigentlich nicht an die offene See, soondern nur an einen fast dem Binnenwasser vergleichbaren Heeresarm stösst. Der Meeresgrund ist bier iberall etwas steinig, wenn auch lange nicht in dem Maasse, wie dies in Sassnitz der Fall ist.

Wo der Meeresgrund sandig ist, da fadet sich keine Spur von Vegetation darau yor, wenigstens in der Nähe des Ufers nicht. Der Boden ist so fest, wie eine Tenne, nur nicht so eben, sondern van kurzen, ziemlich tiefen, welligen $\mathrm{Er}^{*}$ hebungen und Vertiefungen durchsetzt. Wo dagegen Steine liegen, da setzen sich seh" bald kleine Meeresalgen an, deren zarter Ban für das Milroskop die klarste Jebersicht über die Wachsthumsverhältnisse gestattet; später liommt Secgras, derbere Kryptogamen und namentlich an geschützten Stellen grosse Fucusfelder. Ein solches übersieht man z. B. von der Südküste der Greifswalder Oie in grosser Erstreckung. Indess gestattet das bewegte Meer keine selrr dichte Entwickelung: Jeder, anch anässige Sturm wirf grosse Massen ausgerissener Pflanzen auf den Strand, and es ist besonders interessant zu selen, wie die Wellen dem Ufer diese Produkte nicht gemischt zufübren, sondern an einer Stelle Tang (besonders Fuczs vesiculosus), an anderen Seegras (Zostera marina), an noch anderen den aus kleinen Algen und andern Kryptogamen zusammengesetzien ,Seenist" auswerfen. Man kann mit einiger Aufmerksamkeit auf diese Weise am. Ufer eine Uebersicht über die topographische Verschiedenlieit des vorliegenden Neeresbodens gewinnen, deno auch die kleinen Muscbeln, die Rollsteine, der Bernstein und die Kohle, der rothe und sehwarze Seesand liaben ihre oft sehr nalse liegenden Landungsplätze. An gewissen Purkten bringt anch jeder Sturm mächtige, tafelfömige Klumpen eines groben, mit wohlerhaltenen Pflanzenresten durchsetzten Torfes herans, der jedoch wahrscheinlich eire Süsswasserbildung ist und auf altere Verluste der Küste an die See hinzudeuten scheint. Indess sind alle diese Produlite nicht so massenhaft, dass dadnrch der trefflichen Beschaffenheit des Strandes Abbruch geschipht, und namentlich an der Küste der Oder-Inseln findet sich ein glatter, fester Strand so hiberwiegend; dass jeder Ort die schönsten Badeplätze für sich auswählen kann.

II.

Neben der Beschaftenheit des Bodens ist es am meisten der Zustand des Wastetrs, welcher bei der Wabl der Badeorte bestimmend wird. 


\section{5}

Es ist bekannt, dass die 0stsee weder Ebbe noch Fluth hat und dass ihr Wasser weniger salzig ist, als das eigentlich uceanische. Ein paar Angaben über den Salagehalt finde ich boi Mosch (Taschenbuch für Badereisende. 1821). Nach Link. nämlich enthielte 1 Pfund Ostseewasser 87,66 Gr. Kochsala, 4 Gr. Kalksnlphat, 0,66 Gr. Magnesiasulphat, 37 Gr. Chlormagnesium, 0,33 Gr. Harzstoff und seine Temperatur schwankte zwischen $59-61^{\circ} \mathrm{F},\left(15-16^{*} \mathrm{C}.\right)$ in Travemünde berechnete $P f a f f$ dagegen in einem Pfund nur 56 Gr. Kochsalz, b Gr. Kalksulphat, 24 Gr. Chlorcalcium, 1 Gr. Kalklsarbonat, 6 Gr. Culormagnesium. Die Angabe von Hermbstädt (Encyklop. Wörterb. der Berliner med. Facultät. Bd. IV. S. 543) erscheint seln zweifelhaft. Er soll ausser 0,507 freier Salzsäure 15,755 Chlormagnesium, 4,450 Chlorcalcium, 4,859 Bochsalz, 0,275 Chlorkalium, 0,335 Chloreisen, 1,597 schwefelsaures Natron und 0,004 schwefelsauren halk gefunden baben. Kind (chendas. 1844. Bd. 32. S. 683) erzählt, dass "nach dea neuesten Untersuchungen" auf 16 Unzen $0,94 \mathrm{C}$. Z. freie Kohlensäure und auf 1000 Theile des bei anhaltend schönem Wetter geschöpften Wassers in Swinemünde 12,38 Kochsalz, 1,12 Chlormagnesium, 0,67 Cliorkalium, 0,56 scliwefelsaurer Kalk, 0,94 schwefelsaure Magnesia, endlich Spuren von kohlensaurem Eisen- und Manganoxydul, Kalk and Magnesia, Phosphorsäure, Brom, Jod und organische Materie kommen. Inzweifelhaft finden hier noch grössere Verschiedenheiten Stath, zumal in der Nähe der bedeutenden Flussmündungen. Dies dürfte namentlich für die Küste von Swinemünde gelten, wo der tiefste der aus dem Haff kommenden Dder-Arme, die Swine, sich in das Meer ergiesst.

Wie bedentend die Beimischungen sein können, die auf diesem Wege dem Meerwasser zugeführt werden, sals ich namentlich in diesem Jahre während der Zeit, wo die Oder jene ungeheueren Leberschwemmungen machte, von denen ein grosser Theil der schlesischen Ebene ïberfluthet wurde. Wäbrend unerhörte Massen atmosphärischer Niederschläge in Oberschlesien erfolgten, hatten wir an der Kinste anlialtenden Seewind, welcher das Ausströmen des Flusswassers in der Art beeinträchtigte, dass nicht bloss auch das ganze untere Oderthal in der Mark und in Pommern unter. Wasser gesetzt wüde, sondern auch die südlichen Uferstrecken der Insel Usedom vom Acliterwasser her weit und breit iiberschwemmt wurden. Als der Seewind etwas nachliess, erfïllte sich das Meerwasser dermaassen mit feiaen, grünlichen Flocken, dass es ganz undurchsichtig wurde und bis auf eine befrächtliche Erstreckung von der Kïste ein trübes, dickes Ausselien annahm. Diese grïnlichen Flocken, welche sich schliesslich zu einem grosæen Theile am Strande absetzten, bestanden überall ans feinen, im Zerfal! begriffenon, körnig gewordenen Pflaazenresten, meist aus schr schmalen und langen, dicht aneinander gedrängten Zellen zusammengesetzt. Die Fischer meinten, die See, ,blühe", allein dieselben Nassen erfüllten auch das Achterwasser, einen grossen, mit der Peene in Verbindung stehenden Binnensee, der sich meilenweit durch das zerrissene Südland von Usedom erstreckt und weiterhin mit dem Haff zusammenhängt. Ueberall, wo das. Achterwasser auf die Wiesen übertrat, überzogen sich die Gräser mit einer ähnlichen, blau-grünlichen Lage, welche genau dieselbe mikroskopische Zusammea-. zetzung hatte, wie die im Meere sehwimmenden Flocken. Es scheint mir daher 


\section{6}

ziemlich sicher zu sein, dass das Mee seino Beimischungen von den Binnengewäs. wern nugeführt prhielt. Allein diese Beimischung war so massenhaft, dass es weniggtens an einem Tage unmöglich schien, im Meere zu baden.

Was die Temperatur des Meerwassers betrift, so kan leh däüber nichts Allgemeines beibringen. Kind giebt von Swinemünde an, dass die Wasserienperatur in den Monaten Juli bis September zwischen 11 und $19^{\circ}$ R. schwanke, jedoch meist nur zwischen $13-15^{n}$ wechsele. Gewiss ist, dass die Temperatur an masereñ fachen Küsten wenig constant ist. Wenn die See selur ruhig ist, was bei anhalendem Landwinde der Fall ist, so erwărmt sich die in der Nähe ảer Küste stehende, relatis geringe Wasserschicht allmälich, und ich fand einmal bei einer Lafternperatur von $12^{\circ}$ R. das Wasser nahe am Strande fast von derselhen Temperatur. Bei Stürmen ändert sich dieses Verhältniss, indem dann nicht bloss das Wasser aus grösseren Meerestiefen leranfgebracht, sondern auch durch das Entstehen von Strömungen aus grösseren Entfernungen, wabrscheinlich selbst von der hohen See her, Zuflüsse relativ kälteren Wassers erfolgen. Im Allgemeinen dürfte es aber wohl richtig sein, in der Nähe flacher küsten eine relativ höhere Wassertemperatur anzunehrnen, und ich halte dies für einen wesentlichen Grund, wesshalb man gerade an den Ostsecküsten eine nicht zu frühe Jahreszeit zum Baden wählex sollte. Auf die Vorzïge der Herbstbäder werde ich noch zurücklommen.

Ausser dem Salzgehalt und der Temperatur des Wassers ist besonders Gewicht zu legen auf den Wellenschlag. Burmeister hat in der Schilderung seiner Reise nach Brasilien (Geologiscle Bilder 1853. Bd.II. S. 24 a.) die Abhängigkeit der Wellenbildung won den Luftströmngen in eben so klarer, als umfassender Weise dargelegt, wenn er aucl vielleicht gewisse nor quantitative Verschiedenheiten der oceanischen Wellen von den litoralen und denen der 0stsee inshesondere etwas zu sehr als qualitative aufgestell liat. So habe ich mamentlich die secundären und tertiären Wellen, welche sich auf der Rücken der grossen, primären Wellenberge bilden, auf dev 0stsee, ja sogar auf der Höhe des Achterwassers bei recht frischer Brise aufs Deutlichste verfolgen können. Bei dem Mangel an Ebbe und Fluth ist aber an der Ostsee-Küste jede Oberflächen-Bewegung einzig und allein von der Luftströmung abhängig, und da bekanntermaassen unser Binnenmeer won sehr wechselnden, dem Schifer nur zü gefährlichen Winden heimgesucht wird, so wechselt das Ausselien des Meeres und der Zustand der Küste manclimal fast jeden Tag. Bei recht vollständiger Windstille Jag die See als ein vollständigg glatter Spiegel da, dessen weisslich-blane Grundfarbe nur durch die Reflexe der verschieden gefärbten Wolken unterbrochen wurde; an dem weithin trocken gelegten Ufer klatschte nur in langen Zwischenräumen eine matte Welle an und in der See sah man Laum die Stellen der Riffe durch eine sanfte Kräuselung der Obernache angedeutet. Und schon an nächsten Tage brach ein Stum herein, der die Wellen schäumend aus der düstern Fläche des Meeres emporwarf, den Strand bis zu den Dünen überfluthete und die sorgsamen Anpflanzungen des Strandhafers, mit dem man den losen Sand der Dünen zu befestigen bestrebt ist, in langen Strecken unterwühlte und mit den Dünen hinwegriss. Wie oft sahen wir diese achrellen Uebergänge vom Sturm zur Stille und ron der Ruhe zur Unuhe, wie 


\section{7}

Qft gingen wir trockenen Fusses, wo ein paar Tage zuvor die stärkste Brandung aufschlug! Welch' ein eigenthümlicher Reiz liegl in dieser ewigen Neuheit des doch so bekannten strandes, den wir um so schneller lieh gewinnen, als seine oft so schnellen Verluste uns selbst mit dem Gefüll ejner spannenden Unsicherbeit erfüllen. Wir nehmen Theil an seinem Geschich; wird morth noch rorhander sein, wo wir heute, weitab von dem Rande des Wassers; sicher wandeln?

An der ganzen Käste von Pommern ist der beste Wellenschlag tnit dem an sich vorherrschenden Westwinde verbunden. Dieser ist so überwiegend, dass die meisten einzeln stehenden Bäune, daher am meisten die an den Wegen und in den Gärten yom Westen her etwas niedergedrückt sind. Namentlich ist der Nordwest in der späteren Jahreszeit sehr häufig. Die Wellenbildung gestaltet sich dan um so erfreulicher, als die Nord- und Westwinde das Wasser über die langen Riffe hinwegwerfen müsseu, wetche vor der Küste hinlagern. Hier bilden sich denn durch die Reibung des Wassers gegen den Boden des Riffes die stärksten Wellen, und wenn man eine Stelle des Strandes triff, wo man fon Ufer aus eine zwischen zwei Parallelrifien gelegenen Meeresstelle erreichen kann, so findet man einen Weilenschlag, der in der That nichts zu wünschen übrig lässt. Die Gewalt der Wellen ist hier nicht so gross, dass man jeden Augenblick davon überfluthet wird, aber doch so stark, dass man einige Aufmerksamkeit und Anstrengung nöthig hat, um sich vor empfindlichen Einwirkungen zu bewalıren.

An ziemlich nahen Punkten der Küste jst übrigens der Wellenschlag nieht gleich, auch wenn ihre Situation auf den ersten Blick ziemlich ïbereinstimmend ist. Zum Theil hängt dies von der Tiefe des Wassers am Ufer ab, da natürlich an einem sehr flachen Strande die Wellen sich früher erschöpfen. Allein sehr wesentlich scheinen darauf gewisse Strömungen Einfluss zu haben, wie sie bei Rügen und den Oder-Inseln wahrscheinlich schon seit langer Zeit bestehen, möglicherweise zusammenhàngend mit den durch den Sund und die Belte gehenden Strömungen. Die Hauptrichtung derselben entspricht der herrschenden Windrichtung, ist also namentich von Nordwest gegen Südwest gehend, und ihre Gewalt ist am stärksten bei grossen und anhaltenden Nordweststürmen. Auf Usedom sieht man ihre Einwirkung an meisten an dem westlichen Ende, inshesondere am Streckelberg und etwas westlich davon, wo das vielbesungene Riff von Vineta sich ausbreitet. Noch melir tritt dies jedoch auf Rïgen hervor, das von zahlreichen, zusammenhängenden Yeeresbuchten und Inwicken, die alle von Nordwest gegen Südost gerichtet sind, förmlich zerrissen ist, und an dessen Südostende jene sonderbare Inselgruppe liegt, deren Entsteling nicht bloss die einheimisehen, somdern fast noch mehr die skandnavischen Forscher so viel bescbäftigt hat.

Dieses ganze Terrain ist klassischer Boden. Die isländischen Sagen und die dänischen Geschichtsschreiber wissen viel davon za erzählen. Die Delta-Inseln der Oder sind jenes viel besprochene Jome oder Jumne, auf dem die Seekönige des Nordens ihren spartanischen Staat errichteten. Ihre Seeburg (Jomsburg, Jumneta, davon durch einen Schreibfehler Vineta), deren Beziehungen zu dem späteren Julin oder Wollin noch immer nicht hinreichend aufgeklärt sind, ist auch von den neuezepn Dichtern oft gerug gefeiert worden, und der Stifter des Vilinger Staates, Palną- 
tokke, haz belanntlich den Forschern de Tell's-Sage die gróssten Schwierigkeiten bereitet. (vergl. Giesebrecht, Geschiehte der Freibenter ron Jom und Vedel Simonson's Gesehichtliche Untersuchungen itber Jornshurg im, Wendenlande in den Baltischen Studien. 1927. S. 90 и. 176; W. Dönniges, Vinela oder die Seekönige der Jomsburg. Berlin, 1837, sowie 0ehlenschlägger's Palnatokké). Allein wo immer Palnatokle seine Jomsburg begründet haben mag, das scheint nicht abzuleugnen zla sein, dass seit historischer Zeit hier grosse Verluste an die See stailgefunden haben. Um das Jahr 1000, wo die berïhnte Seeschlacht bei Swolderoe, der heutigen Greifswalder Oie, zwischen den nordischen Königen geschlagen wurde, in der Olaf Trygwåson von Norwegen das Leben verlor, mussten die Küstenverhatht nisse noch ganz andere sein. Mohnike hat in seiner Bearheitung der Beimsirringla Saga (Sagen der Könige Norwegens von Snorre Siurleson. Aus dem Isländischen. 1837. Bd. I. S. 555) entwickelt, wie grosse Zerstörungen hier stattgefunden haben müssen, und wenn man dazu nimmt, dass die alteren pommerschen Geschichisschreiher, namentlich liantzow und Micrälius den grossen Sturm, durch welchen der Ruden an der rügianischen Halbinsel Reddewitz oder Mönehgat abgerissen wurde, in das erste Decennium des 1 ften Jahrhunderts setzen, so wird es allerdings nicht unwahrseheinlich, dass früher ein mehr oder weniger zusammenhängendes Land bestanden habe, wo jetzt fast nur noch der Ruden und die Oie den Wellen einen stets kleiner, werdenden Widerstand entgegensetzen. Während die Küsce. Schwedens sich allmälich hebt, sinkt an unserer Küste Strich um Strich in die Flnthen. Von der mächtigen Tempelburg Arcona's, der nördlichsten Spitze Deutschlands, ist so viel Ininweggestürzt, dass der Rest kein Bild melr von der Feste giebt, weiche König Waldemar 1168 zerstörte. Auch am Streckelberg frisst die See jedes Jahr beträchtliche Stïcke weg, und die langen Züge von Sandbänken, welche sich von der Nordspitze Usedoms, dem durch die Landung Gustav Adolplus in Deutschland berülmten Punte, gegen den Ruden hin erstrecken, lassea der Phantasie Spielraum genug, um darin die Reste blühender Landstriche zu erkennen.

Noch jetzt ist die Strömung an stärissten and daher der Wellenschlag an besten da, wo die Sage dic untergegangene Jomslsurg sieht, westlich rom Streckelberg, sodamn um Heringsdorf und auf der Insel Wollin um Misdroy, tem immer melar aublühenden Badeorte. Dic rügianischen Orte können sich damit auch nicht entfernt messen. Bei Putbus, wo der an sich schöne Busen gegen den rügianischen Bodden, der seinerseits eine kaum als Meerestheil zu bezeichnende Bucht darstell, noch durch die linghingestreckte Insel Vilm abgeschlossen wird, erreichen selbst in stürmischem Wetter die Wellen nicht den eigentlichen Meerescharakter; sie sind kurz, niedrig und wenig eingreifend. Sassnitz und Binz liegen an der östlichen Küste, und namentlich der erstgenannte Ort empfängt wegen seiner mehr südlichen Lage fast immer nur die seitlichen Wellencurven, während die fortschreitende Wellenbildung vielmelor in einer der füste parallelen linie geschieht.

[1].

Wit Recht hat man darauf higgewiesen, dass bei der Wahi aine Badeortes 
die Beschaffenheit des Strandes und des Wassers noch nicht die höchste Rücksicht darstelle, dass vielmehr die Lage, das Klima des 0rtes ungleich wichtigere Gesiclitspunkte biete. Je mehr ein Küstenort sich dem eigentlichen Inselklima nähert, um so gïnstiger wird die Luft für die Kranken sein, und in dieser Beziehung stehen die Nordsee-lnseln gewiss unter den deutschen Seehädern obenan. Unter den pommersehen Inseln wäre hier fast nur die $\mathrm{Gr}$ eifs wa ld er 0ie anzureilhen, die auch sonst in ihrer ganzen Bildung eine grosse Aehnlichkeit mit Helgoland zu erkennen giebt. Von den benachbarten grösseren Inseln, Rügen und Usedom, ist sie überall meilenweit entfernt, ebenso ron dem vorpommerschen Festlande. Dabei ist sie nur 78 pommersche oder beinahe 149 magdeburgische Morgen gross, nur von 3 Bauern' ( 39 Einwohnern) und dem Personal eines Leuchthurmes bewohnt. Sie steigt steil rom Meere auf, meist mit fast senkrechten, gewöhnlich $30-40$, stellenweis bis 80 Fuss hohen Wänden, ist oben fast ganz flach, mit leichter Erhebung gegen Nordosf, selir fruchtbar und mit relativ grossen Waldstrecken besetzt, welche einen doppelten Reiz auf der kleinen Insel besitzen, indem ilbren Hauptbestandtbeil dickstämmige Dornbäume, lie und da mit Stechpalmen untermischt, bilden. Die Einwohner, von dem Verkelhr mit dem Festlande fast ganz abgeschnitten, besitzen noch eine fast patriarchalische Gastfreundschait (vgl. ,über einige Eigenthümlichkeiten des Kirchspiels Kröslin in Net-Vorponmern und der dazu gehörigen Inseln Ruden und $0 \mathrm{ie}^{\prime \prime}$ in den pemmerschen Provincial-Blättern. 1820. Bd. 11. S. 36). Schon öfters ist die Oie, wie das Fremdenbuch des Lenchtthurms ausweist, von einzelnén Badereisenden besucht worden und diese scheinen jedesmal sehr befriedigt géwesen zu sein. Allein für einen grösseren Zufluss von Fremden dïrfte der Raum doch fast za klein sein, und die Ankommenden inüssten sich jedenfalls anf eine grosse Frugalität gefasst machen. Azch scheint die Badegelegenheit nicht allzu günstig zu sein, indem fwenigstens bis jetzt nur. eine Stelle dazu benutzt worden ist, welche unmittelbar an dem einzigen Landungsplatze und dem einzigen grössern Aufgange zur Insel gelegen ist. Es ist dies die südwestliche Spitze, von der aus sich bis auf eine Viertelmeile in der Richtung gegen den Ruden bin ein Steinriff erstreckt, welches aus enorm grossen Geschieben gebildet wird, die auf einer fast continuirlich mit dem Ruden zusammenlängenden Sandbank liegen und zu einem grossen Theile weit über die Meeresfläche hervorragen. Immerbin ist der Aufenthalt auf der mit einer präclitigen Aussicht versehenei Insel einzelnen Besuchern, die keine Ansprïche machen, selır zu empfehlen; namentlich aber schwächliche Personen, welche hauptsächlich Ruhe und eine milde Luft stchen, würden sich in der besseren Jahreszeit hier gewiss sehr wohl fühlen. Noch im September, wo wir die Insel besuchten und eine Nacht darauf zubrachten, empfanden wir den temperirenden Einfluss des Meeres auf die Luft sehr angenehm.

Auf $R$ ügen dagegen ist von einem eigentlichen Inselklima nichts mehr zu finden. Die Insel ist zu gross, das Festland zu hahe, das Land selbst zu boch, um die Einwirkung des Meeres noch hinreichend zuzulassen. Indess bieten durch ilure meàr südliche, geschützte Lage doch manche Orte selu günstige Verhältnisse. Neben dem grossen gesellschaftliclien Comfort, den man in Putbus findet, ist es namentlich seine Lage an dem Südabhange der Küste, welche manche der schoa

Archiv f. pathol. Anat. Bd. VII. Heft 3 u. 4. 
berührten Nachtheile geringer erscheinen lässt, Vor Allem günstig gelegen ist aber Sassnitz, das nach Norden durch die bochansteigenden, mit den schönsten Buchenwäldern bedeckten Kreideberge der Stubbnitz geschützt ist und sich zugleich so dicht bis ïber die See vorschiebt, dass der Aufenthalt daselbst zu den allerreizendsten unserer Gestade gerechnet werden kann. Vor Putbus hat es die unmittelbare Nähe der See, die Abgeschiedenbeit, die prächtigen Berge und Wälder in seiner nächsten Umgebung, namentlich die einzige Stubbenkammer, endlich das noch ganz zatürliche Fischerleben seiner Bewohner voraus. Obwohl das Seeufer selbst, wie schon erwähnt, manche Vortheile vermissen lässt, so ist doch die Zahl der Besucher in einer jäbrlich steigenden Zunahme, und der günstige Einfluss des Aufenthalts daselbst ist so vielfach erprobt worden, dass diesem Orte eine wachsende Theilnalume gewiss nicht fehlen wird.

Auf Usedom sind die Luftverhältnisse 'nach der Verschiedenbeit der Oberflächen-Conformation sehr wechselnde. Während der östliche Theil eine mehr kompakte, von Bergen durehsetzte Landmasse ausmacht, ist der westliche Theil ganz zerrissen. Hier dringt das Aclterwasser mit zahlreichen, kleineren und grösseren Buchten, einzelne Inselchen und zahlreiche Halbinseln bildend, von Süden her ein und nähert sich an einer Stelle, zwischen Damerow und Zempin, den Stranddünen so sehr, dass die Gefabr eines Durchbruches schon seit langer Zcit gefürchtet wird. Bei der grossen Ueberschwemmung dieses Jahres schied fast nur die Düne das frische und salzige Wasser. Quandt glaubt sogar aus einer Stelle des Saxo Grammaticus schliessen zu müssen, dass zur Zeit des Kriegszuges von Waldemar I. um 1175 ein Ausfluss beim Streckelberge stattgefunden habe, eine Annahme, durch welche die Lage der Jomshurg mit der durch die Sage bezeichneten Localität von Vinefa leicht in Uebereinstimmung gesetzt, für welche sogar, wie es mir scheint, manche localen Gründe beigebracht werden könnten *). Mag das aber sein, wie es wolle, so ist es doch sicher, dass das Land hier eine geringe Ausdebnung hat und die Nälı so grosser Wassermassen zu beiden Seiten einen sehr temperirenden Einfluss ausitbt. Leider kann ich dies nicht durch Zahlen belegen, und ich beschränke mich daher darauf, nach Berghaus (Geschichte der barometrischen Höhenbestimmung von Berlin und Dresden. Drei Sendschreiben an A. v. Humboldt. Berlin, 1836) die Zahlen der mittleren Tem-

*) Die Gründe für das Bestehen Vineta's in dieser Gegend hat Meinhold (Humoristische Reisebilder von Usedom. Stralsund, 1837) sorgfältig zusammen, getragen. Man muss hier, wie es mir scleint, wohl unterscheiden. Dass ein Ort mit Namen Vineta in dieser Gegend nie bestanden babe, ist jetzt wohl ziemlich ausgemacht. Aber ebenso ausgemacht ist es, dass die Jomshurg oder Jumneta irgendwo hier gelegen haben mïsse. Dass dies nun nicht gerade da gewesen ist, wo das ron den Küstenbewohnern als Vineta bezeichnete Steinriff, $\frac{1}{8}$ Meile vor dem Strande von Damerow, sich findet, ist wenigstens böchst wahrscheinlich, da die zahlreichen Steine, welche hier zu den Molenbauten von Swincmünde gehoben wurden, wedel eine regelmässige Lagerung, noch regelmässige Formen darboten, wie denn überhaupt in jener Zeit wohl kaum so grosse Granitblöcke zum Aufhau der Burgen verwendet sein möchten. 
peratur für Swinemünde und Stralsund, den beiden nach Westen und Osten gelegenen Städten, zu gehen:

$\begin{array}{lcc} & \text { Swinemünde } & \text { Stralsund } \\ \text { Jahresmittel } & +8.62 & +8.16 \\ \text { Winter } & -0.60 & -1.12 \\ \text { Früliling } & +7.70 & +7.29 \\ \text { Sommer } & +17.75 & +17.07 \\ \text { Herbst } & +9.64 & +9.40\end{array}$

Hier zeigt sich der güustige Einfluss des Neeres in der relativ hohen Herbsttemperatur und der mëssigen Sommerwärme schon sehr deutlich. Und doch muss dies noch weit mehr der Fall in jenen Ortschaften sein, welche dem Meere näher licgen, als Swinemünde, das eine gate Strecke landainwärts angelegt ist und von wo man dalier einen so tüchtigen Spaziergang bis zu den Seebädern machen muss, dass mit Recht die Badegäste schon aus diesem. Grunde lieber andere Orte aufsuchen. Leider giebt es auf der Insel Usedom nicht allzuviel Ortschaften von ganz günstiger Lage und selbst in dem schmalen, nördlichen Theile sind die Dörfer fast alle nicht unmittelbar am Strande angebaut, sondern weit mehr am Achterwasser, wahrscheinlich weil gerade hier das fruchtbare Land sich findet und sowohl die Fischerei, als auch der Binnenverkehr auf dem Achterwasser sehr lebbaft sind. Allein trotzdem, dass man zuweiten 10 Minuten bis $\frac{1}{4}$ Stunde gebraucht, um von den Dörfern zu den Badehütten zu gelangen, haben sich doch mit jedem Jahre auch im westlichen Usedom immer mehr Badegäste eingefunden. Namentlich sind Zinnowitz, am Fusse des schön hewaldeten klülnberges, und Coserow, berïhmt durch die ,Bernsteinhexe" ron Meinhold, sehr in Aufnahme gekommen. Indéss lässt sich nicht lengnen, dass Heringsdorf (abgesehen von dem ilım gegenüber auf Wollin liegenden Misdroy) immer den Vorrang wird behalten müssen. Auf einem prächtigen Rerggelände, das mit ẗppigem Laub- und Nadelholze geschmückt ist, mit der weiten Aussicht auf die See ziehen sich die eleganten Häuser von Heringsdorf in einem grossen Bogen hin. Gegen die Nordwestund Ẃestwinde fast ganz geschützt, vor der heissen Mittagssonne ziemlich gedeckt, mit allerlei Einrichtungen des Comforts und selbst des Luxus reichlich genug versehen, bietet dieses Bad der ermüdeten und doch verwölinten Gesellschaft der grossen Städte, namentlich für die heisseren Sommermonate den angenehmsten Aufenthalt.

Wer geringere Ansprüche macht und das Bad nur des Badens und der Luft wegen aufsucht, am meisten aber, wer ungenirt sein will und sich vor einer allenfalls vorkommenden, etwas unzarten Berührung nicht zu sehr fürchtet, findet dagegen in den westlichen Dörfern Usedoms eine freundliche Aufnahme. Durch eine besondere Gelegenlieit wurde ich veranlasst, das kleinste dieser Dörfer, eigentlich nicht einmal ein Dorf, zu besuchen, das wegen der Nähe des Vineta-Riffes so oft genannte Damerow, das eben gross genug ist, um neben den 4 einheimischen Fischerfamilien noch ein Dutzend Badegäste zu beherbergen. In 3 Minuten waren wir von unserem Hause, das vor den Seewinden durch die Dïnen und ein kleines Wäldchen geschützt lag, am Meeresstrande, und in eben so langer Zeit auch 
an Ryck, einer Hafenbucht des Achterwassers, wo sich gewölnhlich eine kleine Flatille von Binnenfahrzeugen sammelte, welche den weiteren Vertrieb der in grossen Mengen im Meere gefangenen Heringe vermittelte. Ich fand hier die Luft bis in den September hinein äusserst wohlthuend, zumal da die Dïne uns gestattete, je nach der Richtung des Windes unsere Spaziergänge bald längs des Meeres, bald an der inneren Seite im oder am Walde vorzunehmen. Wollten wir böhere Standpunkte, so hatten wir in nächster Nähe den Streckelberg, die bedeutendste Anhöhe dieses ganzen Strandes, die fast 200 Fuss steil zur See abfällt und deren stets nachstürzende, kahle Wand den Schiffern weithin unter den Namen des Witteberges (weissen Berges) zur Orientirung dient. Unsere Boote führten uns leicht zu den benachbarten Orten der Inseln oder des Festlandes, und die mannichfaltige Beschäftigung unserer Nachbaren, welche bald der Fischerei, bald dem Acherban, bald der Jagd oblagen, gewährte uns immer neue Genüsse.

IV.

Nachdem über Land und Wasser berichtet ist, bliebe zunächst übrig, von den Leuten zu sprechen. Bei der grossen Neigung, welche gegenwärtig berrscht, die Eigenthümlichkeiten der Bevötkerungen aus der natürlichen Beschaffenheit des von ibnen bewolnten Landes herzuleiten, wäre das gewiss ein dankbarer Gegenstand, die Eigenthïmlichkeiten der pommerschen Insulaner genauer zu schildern. Indess muss ich bekennen, dass ich den Menschen nicht für ein so cinfaches Product des Bodens, auch nicht für ein so directes Erzeugniss von Essen und Trinken balte, wie die enthusiastischen Vertreter der geologischen und gastronomischen Anthropologie glauben machen möchten. Ich zweifle freilich nicht, dass es möglich ist, gewisse Aehnlichlseiten zwischen Arnold Ruge und Ernst Moritz Arndt zu finden, da sie beide auf Rügen geboren sind; ja man wird vielleicht so glücklich sein, Uebereinstimmungen zu entdecken zwischen Bugenhagen, dem Freunde und Helfer Luthers, der aus Wollin stammte, und dem Dichter der Bernsteinhexe, Meinhold, der das Licht der Welt auf Usedom erblickte und vom protestantischen Pastor sclitiesslich Katholik wurde. Aber sicherlich wïrden diese Männer selbst gegen die Aehnlichkeit viel einzuwenden haben und wahrscheinlich würden sie in den besonderen Verhältnissen ibrer Erziehung und ihrer Entwichelung den Grund ihrer Besonderlieiten deutlicber nachweisen können, als in dem Umstande, $o b$ sie auf der Tertiärformation oder dem Alluvium zur Welt kamen.

Unsere Inselbewohner werden von früh an zu einem thätigen, mancher Entbehrung und Gefahr unterworfenen Leben erzogen, und das bestimmt zumeist die spätere Richtung ihrer Lebensanschauung und die Entwickelung ilres Körpers. Allerdings lässt sich nicht leugnen, dass die Art ihrer Ernährung sehr wesentlich 'dazu heiträgt, sie melır oder weniger leistungsfähig zu machen, und die ländliche Bevölkerung von Rügen, welche neben kräftiger Planzentrost eine verhältnissmüssig reiche Fleischnahrung geniesst, ist so arbeitsfähig, dass die continentalen Arbeiter mit jhr nicht concurriren können und die Gutsbesitzer trotz des höheren Lohnes die einheimischen Arbeiter vorziehen. Allein die ärmere Strandbevölkerung ron Usedom, bei der die Fleischkast sehr spärlich ist und die in Fischen nur 


\section{3}

unvollständigen Ersatz dafür findet, erweist sich doch als eine selır leistungsfähige Man staunt oft, wenn man die rastlose Thätigkeit dieser im Ganzen nüchteraen Leute ansieht. Vor Tagesanbruch ziehen sie hinaus auf die See, um ihre Netze einzuholen, und kaum haben sie ihre Heringe gelandet, sortirt und nach Hause gebracht, so sind sie schon wieder auf ihren Aéckern beschäftigt, um in aller Eile die ländlichen Bestellungen zu verrichten und Nachmittags zur Zeit wieder aufs Boot zu gehen, wo sie ihre Netze oft meilenweit in das Meer hinaissetzen. Und wie oft ist der Fang, den sie thun, nicht der Mühe werth, wie wenig leistet ihnen häufig der durch den Flugsand der Dünen verkümmerte Boden! Aber sie sind genügsam, und wenn auch nur Wenige zu einer behaglicheren Existenz gelangen, so harren sie doch Alle ohne Murren in ihrer angestrengten Thätigkeit aus. Was aber am meisten für sie einnimmt, das ist ihre ordnung und Pünlitlichkeit. Freilich bringt die ganze Art ilurer Beschäftigung, die gewöhnlich in mehr collegialer Weise getrieben wird, eine frühe Gewöhnung an Ordnung mit sich, aber die Sorgfalt, mit der sie ilhre Netze stricken, waschen und auf gemeinschaftlichen Plätzen zum Trocknen aufhängen, übérträgt sich auch auf andere Dinge. Man kann sich auf diese Fischer verlassen; sie erinnern sich ihres Wortes, das sie nach vernünftiger Ueberlegung in ihrer treuherzigen, wenn auch zuweilen etwas groben Weise geben.

Dass der Kreis ihrer Anschauungen kein selur umfassender ist, versteht sich von selbst. Da die meisten von ihnen an ihre Heimath gebunden sind, so kennen sie ausser der benachbarten Küste nur wenig, und ilr traditioneller Patriotismus wird nicht übermässig durch die Vorstellung gesteigert, dass das Meer russisches Gebiet sei. Schon Ad. Stahr hat bei einer früheren Gelegenheit entwickelt, welche sonderbare Vorstellung die Fischer von Heringsdorf damit verbinden, dass die See „kaiserfrei" sei. Auch unsere Fischer wussten nicht anders, als dass das Meer bis an die Küste „dem Russen“ gehöre und dass die Fischerei. darauf nur desshalb ron Abgaben frei sei; ,wenn es des Königes sei, so würden sie gewiss dafür bezahlen müssen", meinten sie.

In Allem, was sie sich nicht selbst bieten können und was ihnen nicht zufällig zukommt, sind diese armen Leute fast ganz verlassen, und es geht ihnen oft sowoll geistig, als hörperlich schlecht genug. In unserer Gegend, welche von den nächsten Städten überall 2-3 Meilen entfernt lag, wurde die Noth zuweilen recht sichtbar, und gerade die ärztliche Hülfe war hier so schwierig zu erlangen, dass ein alter Fischer für die gewöhnliche medicinische und chirurgische Praxis das allgemeine Orakel bildete. Als ich ihm bei Gelegenheit eines Schlüsselbeinbruchs, den er nicht crkannt hatte, weil der kleine Patient die Hauptschmerzen im Arme klagte und die Untersuchung daher nur auf diesen ausgedehnt wurde, den hang abgelaufen hatte, wendete sich die ganze Praxis mir zu. Aber meine kleine Reiseapotheke reichte nicht weit, und wenn es nicht möglich war, durch Mittel, welche das Haus oder das Feld darbot, zu helfen, so war es schwer genug, aus der fernen Stadt das Nöthige zu verschaffen. In schwereren Fällen sind die Leute sonst gewohnt, den Kranken auf einen Wagen zu packen und mit ihm zum Doctor bineinzufaliren; später muss dann oft bloss nach Bericht und in 


\section{4}

absentia des Kranken verordnet werden. Wäre man bei der heutigen Erziebung der Geistlichen weniger darauf bedacht, ihnen eine rein theologische Bildung zu geben; fasste man das Wesen der inneren Mission etwas melr von dem materiellen Gesichtspunkte, wobei ja der geistliche gar nicht. zu kurz kommen würde, so könnte sich die Stellung der Pfarrer" ungleich einflussreicher und segensreicher gestalten. Einige Einsicht in die materielle Oekonomie des Leihes, mässige Ausbildung in der Chemie uud Botanik würden schon sehr viel nützen. Wie jetzt die Sache liegt, könnte der Einwohnerschaft nur durch die Ansiedelung von Districtsärzten genützt werden, deren Nothwendigkeit ich schon bei friheren Gelegenheiten vielfach hervorgehoben habe. Denn die freiwillige Yiederlassung junger Aerzte in so armen Gegenden kann nie erwartet werden, und eine zwangsweise, unentgeldliche Internirung derselben an bestimmten Punkten werden wir nie unterstützen. Der gesteigerte Verkehr von Badegästen bildet aber wenigstens anch in dieser Beziehung einen Fortschritt, indem sich an den besuchteren Orten wenigstens wälrend der Saison Aerzte einfinden, von denen dann auch das einheimische Volk Nutzen bat.

Von endemischen Krankheiten habe ich glïeklicherweise richt viel wahrgenommen. Am meisten scheinen hier, wie ich aus melireren Mittheilungen schliessen muss, Wechselfieber rorzukammen. In der ersten Zeit meines Aufenthaltes war davon nichts walırzunelumen; als aher die grossen Ueberschwemmungen eintraten, von denen ich schon sprach, kamen auch bald Erkrankungen vor. Die ersten Fälle waren in einem Försterhause, das unmittelbar an den dem Achterwasser zunächst gelegenen und zuerst exponirten Wiesen stand; später fanden sich solche auch in unserer nächsten Nähe, jedoch am deutlichsten, als das Wasser zu verlaufen anfing und die Wiesen in einem versumpften und verschlammien Zustande zurückblieben. In Coserow fand sich der erste Fall in einem Hause, dessen fouchter und schmutziger Hof durch einen Abzugskanal mit dem Achterwasser in Verbindung stand.

Die Form; in welcher das Wechselfieber zur Entwickelung lam, war überall, wo sie deutlicher ausgesprochen war, die einer Tertiana mit starken, zum Theil anteponirenden Anfällen und zugleich mit sehr hervorstechenden Digestionsbeschwerden. Die Anfälle wichen auf Chiningebrauch bald, doch hielten leichtere Störungen noch einige Zeit an. Daneben kamen aber auch Fälle mit sehr wenig ausgesprochenen Paroxysmen und sehr unklaren Symptomen vor, die bald mehr wie gastrische, bald mehr wie rheumatisclse Fieber auftraten, jedesmal aber mit ungewölnalich starkem Ergriffensein des Kopfes verbunden waren. Bei einem Manne, der schon längere Zeit an einer Neuralgie des dritten Astes vom Trigeminus litt, steigerten sich um dieselbe Zeit, wo die Intermittenten erschienen, die Anfälle auf eine ansserordentlich heftige Weise, allein das Chinin erwies sich hier wirkungsios, und da alle äusseren, sowolıl einfach, als endermatisch angewandten Mittel, auch die anästhetischen die Schmerzen eher steigerten, so sah ich mich zuletzt auf Chloroform-Inhalationen und Morphium beschränlit. Dies genïgte wenigstens, um den Zustand erträglich zu machen. Bei einem Fischer, einem etwas herabgekommenen Individuum, hatten sich in Anfällen, die der Beschreibung nach die grösste Aehn- 


\section{5}

lichkeit mit denen eines kalten Fiebers hatten, aber mit heftigem Brechdurchfall verbunden waren, meningitische Zufälle entwickelt, welche zur Zeit meines ersten Besuches viel Uebereinstimmung mit den Erscheinungen des Delinium tremens darboten. Locale Blutentziehungen, laalte Ueberschläge und Uebergiessungen, verbunden mit einer anfangs beruhigenden, später ableitenden Behandlung des Digestionstractes, führtén bald Besserung herbei, nur dass noch immer Schwäche der Augen und Neigung zum Schwindel zurückblieb.

Die Wechselfieber gehören aber keinesweges zu den stationären Krankheiten der Insel und einen ausgesprochenen Einfluss anf den Gesammthabitus der Bewohner habe ich nicht entdecken können. Auch die anderen endemischen Leiden, welche man in neuerer Zeit mit dem Wechselfieber-Miasma in Verbindung gebracht hat, fehlen hier. Von Kropf sah ich ein einziges, grösseres Exemplar bei einer älteren Frau, und die Geisteskranken, die mir vorkamen, hatten niehts von dem cretinistischen Typus an sich. Skrophulöse Kinder giebt es hie und da, und Bucklige, deren Rückgrathsverkrümmung aus skrophulöser Spondylitis hervorgegangen zu sein schien, fehlen nicht, doch ist ihre Zahl gering.

Im Ganzen kann man daher woll sagen, dass dieser Landstrìch der Gesundheit zuträglich und dass die allgemeinen Störungen, welche sich fanden, mehr vorübergehenden Einwirkungen zuzuschreiben sind. Die- höher gelegenen Orte, wie z. B. Heringsdorf, sind auch diesen Einwirkungen nicht einmal zugänglich.

V.

In Beziehung auf die allgemeinen Vorzüge der westpommerschen Seebäder ergiebt sich nach dem Vorstehenden, dass sie eine sehr grosse Mannichfaltigkeit der örtlichen Verhältnisse darbieten nud daher je nach der Natur des einzehnen Falles eine relativ grosse Auswahl gestatten.

Die vorzüglichsten und wahrscheinlich noch auf lange Zeit weit hervorragenden Einrichtungen besitzt Putbus. Die Munificenz seines letzten Herrn, mit dessen vor Kurzem erfolgten Tode der regierende Mannsstamm eines eingebornen, schon vor der Einführung des Christenthums auf Rügen blühenden Fürstengesclilechts erlosehen ist, hat diesen 0rt aufs Prachtvollste ausgestattet, und der in mehreren Jahren wiederholte Besuch des Königs von Preussen hat die an sich glänzende Gesellschaft, welche sich während der Saison in Putbus sammelt, noch mehr gehoben. Theater und Reunionen füllen die Zeit aus, welche das Baden, das Promeniren in dem schönen Park, die Ausflüge in die reizende Nachłarschaft, namentlich auf das hochgelegene Jagdschloss und auf den ganz Rügen beherrschenden Rugard bei Bergen übrig lassen. Auch ist Gelegenheit gegeben, in dem Badehause Bäder mit erwärmtem Seewasser zu nehmen. Allein trotzdem lässt sich nicht leuguen, dass Putbus den Anforderungen, welche man an ein Seebad macht, nicht ganz genügt. Die stadt liegt zu weit von dem Strande entfernt; der Weg bietet wenig Schatten; das Meeresufer selbst ist, wie schon erwähnt, nicht sebr günstig, und es ist daher leicht begreiftich, dass ohne die besonderen Anziehungspunkte, welche der Ort für die reichere Gesellschaft darbietet, es seine Position als Seebad nur schwer würde behaupten können. 


\section{6}

Es ist daher nicht zu verwundern, dass schon seit langer Zeit Swinemünüt eine grösšere Anziehung für Badegäste ausgeübt hat. Die grössere Nähe von Stettin, der häufige Verkehr, der sich hier entwickelt hat, seitdem Swinemünde durch die Eisenbahn gewissemassen der Hafen von Berlin geworden ist, das freiere, gesellschaftliche Leben, endlich die Nachbarschaft der offenen See und bessere, auch für Warmbäder sorgende Einriebtungen fielen hier mächtig ins Gewicht. Swinemünde verdankt es gewiss diesen Vorzïgen, dass es lange Zeit einer der bedeutendsten Badeorte gewesen ist und dass es noch jetzt ein zahlreiches Publilium sammelt. Aber gerade für die Bewohner grösserer Slädte ist es ungleich anziehender, auf dem Lande zu wohnen; und da die Stadt hier eine nicht unbedeutende Strecke vom Meeresufer entfernt liegt, das Ufer selbst selı flach und in der Nahe des Hafens etwas steinig ist, so erklärt es sich leicht, dass links Heringsdorf und rechts Misdroy in kurzer Zeit zu einer grossen Entwickelung gelangt sind. Die unmittelbare Nähe des Strandes, die beträchtlichere Erhebung der Küste, die Waldnachbarschaft geben diesen 0rten einen Reiz, der böclrstens von Sassnitz auf Rügen übetroffen wird. Allein Sassnitz ist ein noch in der Entwiclielung begriffener Ort, dem noch viel von der Behaglichkeit abgelt, welche namentlich Heringsdorf darbietet, und der Strand ist, wie schon geschildert, so wenig gïnstig zum Baden, dass in dieser Beziehung eine Concurrenz überhaupt unnöglich ist.

Immerhin lässt sich nicht leugnen, dass die Stranddörfer weitaus den Vorzug vor den grösseren Orten besitzen. Wer melır die Gesellschaft liebt, wer den $Z$ wang nicht scheut, den die elegante Welt um sich verbreitet, wer an einen bestimmten Comfort gewöhnt ist, der wird Heringsdorf oder mindestens Misdroy aufsuchen. Wer ungebunden leben will, wer den Yerkehr mit der einfachen Bevölkerung des Landes erträgt, wer sich zugleich nach Ruthe sehnt, der wird in den abgelegeneren Dörfern sich mehr befriedigt finden. Und hier kann es nicht zweifelhaft sein, dass für den, welcher lauptsächlich die Seeluft geniessen will, Sassnitz die prächtigste Lage darbictet, während die Strandäörfer von Usedom und Wollin, doch anch in ganz varzüglicher Weise die von Hinterpommern die bessere Gelegenheit zum Baden besitzen. Da tun zugleich fast in der ganzen Ausdehnung der Küste sowohl von Hinterpommern, als von den Oder-Inseln der Strand flach und durch seine Festigkeit zum Gehen höchst geeignet ist, auch die Dünen fast überall den Landwind abschneiden, so dürfte sich für nicht zu schwächliche Personen gewiss diese Gegend am meisten eignen.

Denn es muss ein sehr grosses Gewiclt darauf gelegt werden, dass der Badende viel die Seeluft geniesst und durch ordentliche liôrperliche Bewegung die Wirkung des Bades unterstützt. Man empfindet diesen Einfluss in sehr kurzer Zeit. Die Luft ist, wie namentlich schwächliche und zu Erkältungen disponirte Individuen fast unmittelbar wahrnehmen, ganz verschieden von der Landluft. Ihr Reichthum an Wassertheilen und ihre grössere thermische Beständigkeit temperiren ibre Einwirkung auf die Haut und auf die Schleimhaut der Nase nnd der Lungen. Katarrhalische und rheumatische Dispositionen mindern sich, und selbst bei heftigem Sturm bekommt die Haut nicht jene lästige Trockenheit, die Schleimhäute nicht jene oft gefährliche Reizbarkejt, die sich in rauhem Wetter auf dem 
Lande so leicht einstellen. Die Badenden erlangen daher in kurzer Zeit die Fähigkeit, sich anlaltend der Luft auszusetzen und selbst die stärker reizende Einwirkung heftiger Luftströme ohne Nachtheil zu ertragen. Liegt daher der Wohnort, den man sich wïhlt, nalre genug am Strande, um ihn auch bei schlechterem Wetter leicht erreichen und jede günstige Pause benutzen zu können, so ist es möglich, in kürzern Zeitfristen Erfolge za erzielen, die man auch bei längerem Aufenthalte nnter ungünstigeren örtichen Verhältnissen nicht walunimmt. Namentlich für Leute mit schwacher Brust und zarter Constitution kann der Aufenthalt an der See nur dann günstig wirken, wenn der Strand mögliehst zugänglich und zugleich gegen das Land möglichst abgeschlossen ist, oder wenn der ort ein ausgesprochenes Inselklima besitzt.

Hre volle Bedentung erreicht die Seebadekur, abgesehen von dem günstigen Einfluss der Ruhe und Sorglosigkeit, welche der Kranke hier geniesst, hauptsächlich dann, wenn die combinirte Einwirkung der Seeluft und des Seewassers dureh geregelten und anhaltenden Muskelgebrauch unterstützt wird. Alle künstlichen Nachbildungen können daber den vollständigen Werth eigentlicher Seebäder nicht erreichen. Schon das Baden in einer mit tüclutigem Wellenschlage versehenen See macht ungewöhnliche Kraftanstrengungen nöthig; noch melr ist dieses beim Schwimmen der Fall. Ich halte das Schwimmen überliaupt für so ausnehmend nützlich, nicht blos wegen der allgemeinen Kraltentfaltung, welche damit verbunden ist, sondern noch weit melir wegen der geordneten and zugleich energischen Respirationsbewegung, welehe dabei nöthig ist. Diese Gymnastik des Thorax ist durch keine andere Thätigkeit so leicht zu erreichen, und ich kann dalier denen, welche nicht schwimmen können, nur anrathen, dass sie in möglichst tiefes Wasser gehen und her eine recht systematisehe Reihenfolge ergiebiger Inspirationen unter gleicluzeitiger Muskelbewegung der Extremitäten eintreten lassen.

Dabei ist es aber, wohl in Obacht zu nelmen, dass man nicht zu lange in Wasser bleibe, weil die Hauptwirkung des Bades darin bestehen soll, einen kräftigen Reiz auf die ganze Körperoberfäche auszü̈ben, was natürlich nicht eintreten wïrde, wenn die Einwirkung eine zu protraliste und daher melr oder weniger herabstimmende wäre. Ein Aufenthalt von 5-8 Minuten dürfte fast immer genügen; bei kaltem Wasser und angegriffenem Körper ist auch das noch zu viel. Im Allgemeinen folgt aber đaraus die grössere Nützlichkeit der Herbstbäder. Im Sommer, wo man genötbigt ist, der Abkühlung wegen zu baden, geht an sich durch die längere Dauer des Bades die kräftigende Erregung der peripherischen Theile etwas verloren, und was noch bleibt, das scliwindet durch die holse Temperatur der Luft. Im Herbst dagegen vereinigen sich alle Vorzüge. Unser Meer ist dann an sich bewegter, die Stürne häufiger, der Wellenschlag energischer. Die Temperatur der Luft ist niedriger, die Diferenzen zwischẹn der Luft- und Wassertemperatur geringer, und man wird genöthigt, durch Spazirgänge nach dem Bade die activen Wärmequellen des Körpers in Anspruch zu nehmen. Daher steigert sich so bald der Appetit und man nimmt ganz ungewöhnlich grosse Speiseportionen zu sich, ohne davon belästigt zu werden. Der Stoffverbranch wird um so reger, als die Erregung der Hautnerven auch cräftigere Reflexbewegungen des Digestions- 


\section{8}

tractes hervorruft. Gerade an der 0stsee badet man vielfach zu frülı; die ziveite Hälfte des August und die erste des September dürften woll als die günstigsten Zeiten bezeichnet werden können.

Die danernde Kräftigung des Körpers, welche man von dem Seebade erwartet, kann nur dann erwartet werden, wenn sowohl die nutritiven, als die functionellen Thätigkeiten hinreichend angeregt werden. Daher muss man sich gewissen Anstrengungen und Mïhen unterwerfen, deren Ertragung hier ja ausserdem so leicht ist; Bewegung und Lufthad müssen das vervollständigen, was: das Seebad eingeleitet hat. Auf den Wellenschlag kommt dabei viel an, denn or ist ein ungleich stärkeres Erregungsmittel, als die salze des Meerwassers, deren grösserer oder kleinerer Gehalt wohl keinen grossen Unterschied bedingen möchte. Die einzige Erscheinung, welche vielleiclit dem Salze zugeschrieben werden könnte, ist ein juckendes Erythem, welches sich nach einiger Zeit, namentlich am Rücken ausbildet. Es scheint wenigstens nm so leichter zu entstehen, wenn man sich nach dem Bad nicht abtrocknet, sondern die Wäsche so viel als möglich auf die noch nasse Hant anlegt, wie es von Einzelnen als besonders nützlich angepriesen wird. $0 b$ indess dieses Erythem einen erheblichen Einftuss auf den Gang der Kur hat, weiss ich nicht; ebensowenig als ich behaupten kann, es sei nützlicher, beim Baden etwas Seewasser zu verschlucken, wie manche Badegäste absichtlich thun.

Dagegen ist es durchaus nothwendig, während des Badens die Druckverhältnisse des Körpers möglichst gleichmässig einzurichten und demnach sowohl im Anfange den Kopf sofort unter Wasser zu bringen, als später ibn hänfiger so tief als möglich unterzntauchen. Versäumt man diese Vorsicht, so bilden sich um so leichter Blutstockungen im Kopf und Gesicht, als die erschwerte Respiration, zumal bei schwächlichen und ängstijchen Personen den Rückfluss des Venenbluts vom Kopfe hemmt, und es können dann anhaltende Kopfschmerzen ungleich leichter entstehen, als durch die viel angeschuldigte Nässe der Haare. Dass Personen, welche zu apoplektischen Zuständen disponirt sind, in der See zu grosse Gefahren laufen, als dass sie überhaupt baden sollten, liegt auf der Hand.

\section{VI.}

Obwohl ich mich für naturhistorische Untersuchungen nicht speciell vorbereitet hatte, so führte mich die Gelegenheit doch auf einige Objecte, deren genauere Verfolgung ich allerdings nicht unternehmen konnte, da mir ausser meinem Reise-Mikroskop nur erst in der letzten Zeit einige Reagentien zugänglich wurdea.

Der erste Sturm, den wir an de: See erlebten, warf eine Menge Medusen anf den Strand. Schon früher hatte die eigenthümliche Gallerte der Scheibenquallen meine Aufmerksamkeit erregt, und wenn ich damals die Vergleichung, welche die Schriftsteller der naturhistorischen Schule zwischen dem Gewehe der Medusen and manchen patliologischen Gebilden anstelten, nicht sebr begründet gefunden hatte, so führte mich doch der Gang meiner neneren histologischen Untersuchungen über die Bindesubstanzen wieder auf diese Frage zurück. Wenn selbst die besseren Zoologen für die Gallertsubstanz der Akalephen keine bessere Vergleichung fanden, als den Glaskörper der Wirbelthiere, so lag es nahe, dieselbe etwas näher 
anzusehen, nachdem es mir gelungen war, den Glaskörper als ein Glied in die Reihe der Bindegewcbs-Bildungen einzureihen.

In der That ist die Aelinlichkeit der Medusen-Substanz sowohl mit dem Glaskörper, als mit manchen Colloidbildungen äusserst gross. Diese zarte Gallerte, welche so leicht unter dem Fingerdruck einreisst und in grösseren, radialen $\mathbf{A b -}$ schnitten zerliziftet, enthält in der geringsten Menge von fester Substanz so grosse Massen von Wasser gebunden, dass, als ich in den letzten Tagen den Versuch machte, die Substanz zu trocknen, um sie später genater zu untersuchen, ich so gut wie Nichts übrig behielt. Auch beim Kochen schrumpfen die grössten Thiere zu kleinen, grauweisslichen Klürnpchen zusammen, die äusserst weich und fast zerfliessend sind, so dass es wohl möglich wäre, sie durch fortgesetztes Kochen bis auf kleine Reste ganz in Lōsung zu bringen. Eine schwache Sublimatlösung erhärtet sie dagegen, ohne ihren Umfang wesentlich zu verändern; sie werdền etwas trübe, erhalten sich aber sonst ganz vortreflich.

An der Küste von Usedom wurde nur die Medasa uurila angetrieben. Meistentheils lebten die Thiere noch längere Zeit, denn ich salh an den zottenförmigen Anhängen sehr schöne Contractionserscheinungen, welche die grösste Aehnlichkeit mit den Zusammenziehungen der Darmzotten der Säugethiere hatten. Dabei kamen Exemplare in allen möglichen Grössenverhältnissen, von $\frac{1}{2}-5$ Zoll im Durclmesser, vor, so dass ich an Stoff keinen Mangel litt. Hätte ich schon damals gewusst, dass über die Körpersubstanz dieser Thiere so wenig bekannt ist, so würde ich grössere Mühe aufgewendet haben als jetzt, wo ich sie nur zu meiner eigenen Belehrung zu untersuchen gedachte. Ich bescluarrike mich daher im Nachstelienden atch auf diejenigen Theile, deren Beschaffenheit für die vergleichende Histölogie des Bindegewebes einigen Werth hat.

Betrachtet man die Scheibensubstanz der obrmeduse, so liegt es sehr nahe, dieselbe mit dem von mir beschriebenen Schleimgewebe zusammenzubriagen. Aucli ist die Aehnlichkeit mit Schleim gross genug, tim dem Laien bemerkbar zu werden *). Indess will ich gleǐch vorweg erwähnen, dass es mir weder malkrochemisch, noch mikrochemisch gelang, Schleimstoff als die Grundlage des Gewebes nachzuweisen, ein Umstand, der jedoch nicht hindert, das letztere als ein dem eigentlichen Schleimgewebe wenigstens selr naliestehendes zu betrachten.

Siebold (Vergl. Anatomie 1848. S. 57) bemerkt ganz allgemein: „der Körper der Quallen wird fast durchweg von eifter gallertartigen, aus polyedrischen Zellen zusammengesetzten Masse gebildet." Davon habe ich gar nichts wahrnelmen können. Ich fand vielmehr die Verhältnisse ganz so, wie Ehrenberg sie von der Ohrmeduse der Ostsee abbildet (Abhand. der Berliner Akademie aus dem Jahre 1835. S. 205. Taf. VI.). Seiner Beschreibung dagegen kann ich nicht so

*) Es scheint sogar, dass der Name Quallen etwas der Art- bedeutet. Zö IIn er giebt geradezu an, dass Kwalle holländisch Schleim lieisse, was ich in den mir zugänglichen Wörterbüchern nicht finde. Unsere Fischer nannten diese Dinge, die sie übrigens nicht für Thiere anerkannten, Seegloor, was so viel heissen soll als Seegallerte. Uebrigens bedeutet Qualster im pommerschen Plattdeutsch, wie Kwalster holländisch, den schleimigen Mundspeichel. 
unbedingt beistimmen, zumal da sie auf Beobachtungen bei zu chwacher Vergrösserung gestützt ist, und noch weniger scheint mir die Deutung haltbar, welche er den Elenenten der von ilm übrigens etwas stiefmütterlich behandelten Gallertscheibe hat angedeihen lassen.

Zunächst fand jch an der äusseren Oberfläche ein deutliches, polygones Epithel, das freilich durch körnige Massen getrübt war, von dem sich aber durch Reagentien die einzelnen Elemente rollständig trennen liessen. Diesem Epithel, dessen Existenz Ehrenberg leugnet, indem er die Begrenzungen der Zellen für ein besonderes Fadennetz ausgiebt, gehören auch die von diesem Forscher (Taf. V. Fig. 1.) beschriebenenen ,haufenweise gestellten schïsselförmigen Irörper (Saugnäpfchen) " an, die ich vielmehr für Nesselorgane ansprechen muss. Freilich erregt die Medusa aurita auf der Haut des Mensclien kein Jucken oder Brennen, so dass ich auch der Meinung bin, man brauche sich vor ihnen beim Baden nicht zu fürchten, allein es ist damit nicht ausgeschlossen, dass kleinere Thiere die nachtheilige Einwirknng nicht empfinden sollen. Auf Rügen latte ich eines Tages Gelegenheit, an der Schmalen Heide sehr schöne Exemplare der Cyanea zu fischen, und ich fand hier nicht bloss dieselben Einrichtungen wieder, sondern auch in derselben Anordnung, wie sie Leydig (Müllers Archiv. 1854. Taf. X. Fig. 3.) vor Kurzem von Polypen abgebildet hat. Ich muss daher mit diesem Forscher, sowie mit Carl Vogt ganz übereinstimmen, wenn sie die Nesselorgane zu den epithelialen Gebilden rechnen.

Was sodann die eigentliche Gallertscheibe anbetrift, so giebt Ehrenberg an, dass dieselbe zum grössten Theile aus einer wasserhellen Masse bestehe, „die zahlreiche verstreute Körnchen, wie Drüsen, in sich enthält, welche durch feine Fasern (Gefässe?), nicht Häute, verbunden sind." Später spricht er geradezu von einem ,durch den ganzen Körper verbreiteten feinen und lockeren Netze wahrscheinlicher Gefässe ohne sichtbare Circulation im Innern und zu fein für Blutkörperchen, zwischen welchen zablreiche drüsenartige Körper eingestreut sind." In dieser Bescbreibung ist leider so viel Präjudicirliches, dass Jemand, der die Sache nicht vor Augen gelıabt hat, sich scliwer einen Begrif von dem wirklichen Sachverhalt machen könnte.

Das Gewebe der Gallertscheibe besitzt die grösste Structurähnlichkeit mit knorpel. Ueberall, wo man sie untersucht, findet sich eine schr reichliche, im Ganzen byaline Grundsubstanz, in welche in variablen Abständen, nach aussen zu dichter, nach innen spärlicher rundliche Elemente eingesenkt sind, deren relativ dichtes, liörniges Aussehen sie am meisten Kernen ähnlich sehen ]ässt. Auch ist ihre Grösse wenig beträchtlich, da sie meist nur 0,009 Millim. Durchmesser besitzen. Indess halte ich sie doch für vollständige Zellen, da sich sowoll durch Essigsäure für sich, als namentlich durch Jodnatrium und Essigsäure inn Innern derselben schöne blasse Kerne deutlich machen lassen. Auch an den in Sublimat erhärteten Scheiben finde ich, dass nach Zusatz von destillirtem Wasser der Kern sich deutlich absetzt. Zwischen diesem Kern und der Membran findet sich eine körnige, ziemlich dunkle Masse, aus der sich gewöhnlich noch 1, 2-4 kleine, glänzende Körnchen hervorheben, die durch Natronzusatz, 
Essigsäure ú. s. w. nicht verschwinden und sich ganz wie Fett verhalten. Wir haben es demnach mit einer aus Kernzellen und Intercellularsubstanz zusammengesetzten Bildung zu thun, und das, was Ehrenberg als Drüsen anspricht, wären eben die Kernzellen, denen man allerdings eine gewisse secretorische Function in Bezielung auf die Bildung der Intercellularsubstanz nicht abstreiten kann, die jedoch im Sinne eigentlicher einzelliger Drüsen schwerlich zu deuten sein dürften.

Gegen den Umfang $\mathrm{zu}$, wo diese Zellen dichter liegen, scheinen Theilungen derselben vorzukommen. Hier sah ich wenigstens gekerbte und doppelte Kerne, sehr eng aneinander liegende und gegen einander abgeflachte Zellen. Allein nirgends war ich im Stande, wie Siebold angiebt, die ganze Substanz in polyedriscbo Zellen zu zerlegen, und ich kann daher nur annehmen, dass diese Zusammensetzung gerade der Obrmeduse fehlt, oder dass das polygone Epithel der Oberfäche zu einer Verwechselung Veranlassung gegeben hat. Ich will übrigens sogleich hinzufügen, dass ich bei der Cyanea überhaupt keine Zellen, sondern nur eine Grundsubstanz antraf.

Was nun das Intercellular-Gewebe der 0hrqualle betrifft, so ist es nicht durchaus homogen, sondern, wie Ehrenberg richtig angiebt, von feinen Fasern durchzogen. Diese sind jedoch so zart; dass nach den Erfahrungen, die wir gegenwärtig besitzen, der Gedanke sehr nahe liegt, dass süe nur durch Faltungen und Zerrungen der homogenen Grundsubstanz gebildet seien. Wie schwer es ist, sich vor solchen Verwechselungen zu hüten, zeigt das Beispiel von Don can, der die Schleimfäden des Glaskörpers auch jetzt noch als wirkliche Strukturelemente darstellt (Nederl. Lancet. 1854. Mei en Juny). Ich habe mich daher besonders bemïht, zu erforschen, ob auch sternförmige oder spindelförmige Zellen bei der Meduse vorbanden seien; welche etwa in solche Fäden auslaufen, allein ich habe nichts sicheres gefunden. Allerdings sieht man zuweilen längliche und gezackte Körperchen, allein diese entstehen meist beim Druck oder Zug, oder durch Einwirkung fremdartiger Medien, wie es von den Knorpelzellen bekannt ist.

Nichts destoweniger glaube ich der Grundsubstanz nicht ganz alles Faserige absprechen zu können. Insbesonḋere gegen die oberfläche hin, und namentlich an der Bauchseite fand ich grössere Netze breiterer, anastomosirender, oft sternförmiger Fasern, welche auf dem Querschnitt, wie feine elastische Fasern, mit einem dunklen, innen etwas hellen, kreisförmigen Ende hervortraten, sich zum Theil um den Rand herumschlugen, durch Essigsäure und Natron nicht zerstört wurden, durch Salpetersäure sogar stärker hervortraten, und in dem durch Sublimat gehärteten Präparate nicht bloss sehr deutlich erschienen, sondern auch isolirt aus der Grundsubstanz hervorstanden. Im Innern der Scheibe habe ich die ungleich feineren und zarteren Fäden meist nur in mehr parallelem Laufe gesehen, doch auch hier hảben sie eine grosse Constanz. Verbindungen mit den Zellen konnte ich nirgends auffinden und Beweise für ihr Hollsein nicht wahrnehmen, so dass, wenn sie in gewisser. Weise an der Leitung der Ernährungsflüssigkeiten betheiligt sein sollten, diess gewiss nur in sehr beschränktem Maasse der Fall sein dürfte. An den gelrochten Präparaten erschien die ganze Substanz stark streifig. 
und sal vollhommen faserig aus, was jedoch wohl zum grossen Theile den Zusammenschrumpfen zuzuschreiben sein dürfte.

Die Einwirkung chemischer Reagentien anf die eigentliche Gallertsubstanz ergab sehr wenig. Essigsäure machte eine vorubergchende Trübung, die bei concentrirter Einwirkung wieder verschwand; ein Theil des Gewebes löste sich und es blieh ein Jlares Gerïst zurück, welches durch Kaliumeisencyanür etwas dichter und trüher wurde. Salpetersäure machte ohne Trübung die Substanz etwas fester, die Zellen dunkler. Natron zerstörte den grössten Theil. Jod färbte die Zwischensubstanz wenig, die Zellen sehr stark; nachträglieher Zusatz von Sehwefelsäure machte die Färbung dunkler, jedocl gleichfalls die Zwischensubstanz weniger. Bei längerer Einwirkung der Scliwefelsäure wurde die Grundsubstanz zerstört und die Zellen frei. Auch an der gekocluten Substanz war nach dem Zusatze ron Jod und Schwefelsäure nichts Besonderes wahrnehmhar.

Biese Reactionen, welche ich bei dem besten Willen nicht erweitern konnte, geben kein vollständiges Bild von der Natur der Gallertmasse. Am meisten stimmen sie noch mit dem überein, was ich früher bei der Untersuchung der gallertartigen Substanz der Intervertebralknorpel von Kindern gefunden batte (Würzb. Verh. Bd. II. S. 284), und es dürfte daher selır möglich sein, dass wir hier eine Masse antreffen, welche mit der von mir aus dem Eierstock geschilderten Colloidmasse (Berl. Geburtsı. Verh. Bd. III. S. 203) eine grössere Aehnlichkeit hat. Anf alle Fälle liann darüber kein Zweifel sein, dass, bei der auffallend knorpelähnlichen Struktur der Medusen-Scheibe, das Gewebe derselben in die Reihe der Gewebe der Bindesubstanz gezälılt werden muss. Bei einer anderen Gelegenheit werde ich, im Zusammenbange mit den anderen Gallertsulsstanzen, darauf zurïckkommen.

\section{VII.}

Als ein Gegenstand von hohem plussiologischen und pathologischen Interesse ist mir immer die Fettleber ersehienen. Wenn man manche dieser Lebern durchmustert und auch nirgends eine einzige Leberzelle antrift, welche nicht ganz oder mindestens fast ganz mit Fett gefïllt ist, so wirft man sich mit Erstaunen die Frage vor, wie es hier mit dem Secretionsgeschäft stehe. Sind wirklich die Leberzellen die nothwendigen Vermitfler der Gallenbildung, so solite man meinen, es müsste hier gar keine Galle mehr gebildet werden. Wäre es wahr, dass, wie Will und Wharton Jones meinen, die Leberzellen sich selbst auflösten und dadurch die Galle lieferten, so müsste man schliessen, dass in solchen Fällen nicht Galle, sondern Fett secernirt werden würde, und dass die Leber wie cine grosse Talg- oder Schmeerdrüse wirken müsste. Ich habe desshalb häufig die Galle aus Fettlebern mikroskopisch untersucht, allein böchstens selr vereinzelte Fetitropfen wahrgenommen, und die chemischen Untersuchungen von Frerichs (Hannoversche Annalen 1845. Heft 1. u. 2.) haben sogar eine Verminderung des Fettgehaltes, insbesondere Mangel an Cholesterin, gezeigt, während eine Zunahme der transsudirenden Proteinstoffe wahrnelmbar war. Die Analysen, auf welche sich diese Angaben stützen, sind an sich nicht zahlreich genug, um vollkommen schlussfähig zu sein, zumal da man nicht ganz berechtigt ist, die zufallig im Moment des Todes in der Gallen- 


\section{3}

blase vorbandene Flüssigkeit als einen genauen Maassstab für das ganze Secrelionsgeschäft zu betrachten. Ich habe wenigstens immer eine sehr stark gefärbte Flïssigkeit gefunden, auch wo die Veränderung den höchsten Grad erreicht hatte, und ich muss daraus schliessen, dass auch die fethaltigen Zellen immer noch. im Stande sind, mindestens Gallenfarbstoff zu bilden. Denn da dieser im Blute nicht präexistirt, so muss er wohl in der Leber entstehen. Wäre es abcr nothwendig, dass für diese Absonderung die Leberzellen sich aufösten, so müsste doch gewiss auch das Fett mit übergehen. Da dieses nun entschieden nicht der Fall ist, so bleibt kein anderer Sehluss übrig, als dass die Absonderung nicht an die Auflösung der Elemente gebunden ist, dass vielmehr auch die felterfüllten Zellen noch jmmer secerniren können, wenn auch vielleicht in vermindertem Massstabe.

Die Geschichte der Fettleber lässt noch manche andere interessante Betrachtung zu, indess genügt das Gesagte, um zu zeigen, wie wichtig es sein würde, den Gegenstand bei Thieren zu verfolgen, wo ja inşhesondere die Gänse eine so günstige Gelegenbeit hieten. Bei den Fischen hat die Sache noch ihre besondere Anziehung, seitdem der Leberthran einen so grossen Einfluss gowonnen hat. Leider hat $\mathrm{Leydig}$ bei seinen Untersuchnngen über die Haien und Rochen nur den histologischen Gesichtspunkt verfolgt; ich finde bei ihm nur die spärliche Notiz (S. 58), dass die Leberzellen bei den Plagiostomen wegen ihres Inhaltes eben so richtig Fettzellen genannt werden kö̈nten, indern sie von Fettropfen so angefüllt seien, dass der Kern öfters unmöglich zu sehen sei. Es scheint dennach hier der Zustand der Fettleber ein relativ physiologischer zu sein, und wenn man damit die zuckerbildende Eigenschaft der Leber zusammenhält, so dürfte die ganze Frage dadurch eine andere Stellung erhalten. Wie verschieden die sogenannte Fettentartung der Leber von den Zuständen der Fettmetamorphose ist, habe ich schon früber gezeigt (dieses Archiv Bd. I. S. 151 ü. 159). "Die wesentlichste Differenz beruht darin, dass die Zellen unter der Fettmetamorphose zu Grunde geben, während sie bei der Fettleber persistiren. Denn ich habe nie eine Spur von einer Thatsache walurgenommen, welche dafür spräche, dass die Leberzellen unter der Fettanfüllung endlich abstürben oder platzten. Vielmehr scheint es mir unzweifelhaft, dass sie dahei fortbestehen, dass unter Umständen eine Entfernung des Fetts möglich ist und dass die Fettleber eine ganz eigenthümliche Erscheinung darstellt, die mit der zuckerbildenden Function in eine nähere Beziehung gesetzt werden muss.

Ich richtete daher diesem Zustande an der See meine besondere Aufmerksam keit zu, allein die mir gerade zur Hand kommenden Fische boten wenig Material dar. Unsere Fischer beschrảnkten sich wäbrend der ganzen Zeit ausschliesshlich mit dem Heringsfang, und ès ergab sich bald, dass die Leber der Heringe kaum Andeutungen der Fettbildung darbot. Von den sonstigen Fischen kann ich nur den Lachs erwähnen, dessen Leber allerdings an einzelnen Stellen sehr reichliche Fetteinsprengung wahrnehmen liess, während Galle genug vorhanden war. Nichtsdestoweniger war der Zustand so wenig ausgebildet, dass er weitere Schlussfolgerungen. nicht zuliess, so dass ich mich damit begnügen muss, andere Beobachter auf diesen wichtigen Punkt aufmerksam zu machen. 


\section{4}

Dagegen machte es mir viel Vergnügen, bei verschiedenen Fischen, namentich beim Hering, Lachs und der Neunauge die schönste fettige Degeneration der Muskeln zù verfolgen, so ausgeprägt, dass sie das beste Paradigma für den pathologischen Vergang liefert. An deutlichsten und gröbsten findet sich die Veränderung in den Seitenmuskeln der Neunauge. Isolirt man hier die einzelnen Muskelbündel zwischen je 2 Ligamenta intermuscularia, die durcli die schöne Schildèrung von Joh. Müller (Abhand. der Berliner Akademie aus dem Jahre 1834. S. 27) bekannt genug sind; so finden sich quere, den Ligamenten parallel verlaufende Lagen, welche häufig den äussersten Grad von Degeneration darbieten, so dass in der Richtung der Primitivfasern dicke, perlschnurförmige Reihen ron Fetttröpfchen die ganze Masse erfüllen. Bei den Knochenfischen, am, meisten bei Clupea, liegen die fettig degenerirten Muskeln gewöhnlich an einer bestimmten Stelle und sind durch ihre bräunliche Farbe und weiche Beschaffenheit leicht bemerkbar. Macht man einen Querschnitt durch den ganzen Leib, so sieht man zwischen den dorsalen und abdominalen Theil der Seitenmuskeln einen -dreieckigen Paum, in dem eine Masse liegt, welche sich durch ihre bräunliche Farbe scharf von dem hellen Muskelfleisch der übrigen Theile absetzt. Fier sind die Muskeln oft so vollständjg. degenerirt, dass, man in den Schläuchen des Sarcolemma nichts weiter, als eine feinkörnige, fettreiche Masse wahrnimmt, ganz ähnlich, wie es bei den senilen Zuständęn namentlich an den Augenmuskeln des Menschen vorkommt. Welcher Natur sind diese Vorgänge? Sind es natürliche Rückbildungen von Muskeln, die im späteren Leben des Thieres nicht melı nöthig siad? Sind sie abhängig ron den besonderen Lebensverhältnissen der Fische? Gehören sie in das plysiolögische Gebict? Mir genügt es vor der Hand, diese Fragen hin zu stellen. - Sie werden wenigstens darthun, dass es auch für den Pathologen nicht ungütz ist, sich in dem grossen Haushalt der Natur umzuseben, und jch bedaure nichts mehr, als dass Material, Zeit und Hälfsmittel mir nicht in reicherem Mạassstabe zur Disposition gestanden haben. 